\title{
Human breast tissue cancer diagnosis by Raman spectroscopy
}

\author{
H. Abramczyk ${ }^{\mathrm{a}, \mathrm{b}, *}$, I. Placek ${ }^{\mathrm{a}}$, B. Brożek-Płuska ${ }^{\mathrm{a}}$, K. Kurczewski ${ }^{\text {a }}$, Z. Morawiec $^{\mathrm{c}}$ \\ and M. Tazbir ${ }^{\mathrm{c}}$ \\ ${ }^{a}$ Laboratory of Laser Molecular Spectroscopy, Institute of Applied Radiation Chemistry, \\ The Faculty of Chemistry, Technical University of Łódź, 93-590 Łódź, Poland \\ ${ }^{\mathrm{b}}$ Max-Born-Institute, 12489 Berlin, Germany \\ ${ }^{\mathrm{c}}$ Hospital, Oncology Ward, 93-513 Łódź, Poland
}

\begin{abstract}
Differences between Raman spectra of normal, malignant and benign tissues have been recorded and analyzed as a method for the early detection of cancer. To the best of our knowledge, this is one of the most statistically reliable research (67 patients) on Raman spectroscopy-based diagnosis of breast cancers among the world women population. The paper demonstrates that Raman spectroscopy is a promising new tool for real-time diagnosis of tissue abnormalities.
\end{abstract}

Keywords: Breast cancer, Raman spectroscopy, PCA

\section{Introduction}

Among the different spectral techniques, Raman spectroscopy is usually first choice for observing and investigating biological tissue [1-24]. Raman spectroscopy provides important biochemical information, because each molecule has its own pattern of vibrations that can serve as a Raman biomarker. Raman spectrum gives specific information regarding the chemical bonding of molecules related to vibrations and can therefore be used to identify different molecules in a system. Moreover, these vibrations are generally structure-sensitive reflecting structural changes in distinct environment, and the sensitivity to molecular environment of the biological tissue can be employed to recognize subtle changes in biochemistry of a normal healthy tissue and a malignant tissue. Additionally, the Raman spectroscopy is very sensitive to the structure and phase transitions [25-27] which can be very useful in monitoring morphological features, for example, the morphological changes associated with nuclear enlargement, a qualitative indicator of cancer (the nucleus-to-cytoplasm ratio) used by pathologists.

There are many reasons to expect that Raman spectroscopy will be a valuable diagnostic method in breast tissue diagnosis. The main advantages of potential employing Raman spectroscopy are: immediate in vivo diagnosis, reduction the number of biopsies, combination of biochemical and structural diagnosis. The Raman spectroscopy is non-ionizing method, exhibits chemical and structural specificity and has a potential to remove human interpretation. The effort to develop an optical fiber biopsy needle probe

\footnotetext{
* Corresponding author: H. Abramczyk, Laboratory of Laser Molecular Spectroscopy, Institute of Applied Radiation Chemistry, The Faculty of Chemistry, Technical University of Łódź, Wróblewskiego 15, 93-590 Łódź, Poland. Tel.: +48 42 63131 88, 63131 75; E-mail: abramczy@ mitr.p.lodz.pl, abramczy@ mbi-berlin.de.
} 
for breast tissue Raman applications as well as implementation of Raman spectroscopy in real time for medical diagnosis has been undertaken [6,7]. Unfortunately, despite the great interest and effort the Raman technique is still waiting for incorporation into routine clinical care.

\section{Method and experimental}

We have measured the fresh ex vivo breast tissue samples removed during the operation. The tissue has been divided in a hospital into the normal and abnormal parts. The fresh tissue has been measured immediately after delivering from the hospital. The ex vivo samples neither have been frozen in liquid nitrogen for storage nor fixed in formalin.

Raman and fluorescence spectra have been recorded for the ex vivo samples of human breast tissue. We have recorded Raman spectra from 67 patients. For each patient we have measured Raman spectra for the normal tissue and the malignant (or benign tissue) as well as the blood from the circulatory vessels of each patient. The malignant tissue samples were represented by the following types of cancer: infiltrating ductal cancer, infiltrating lobular, mucosinum cancer, intracystic papillary cancer. The benign lesion tissue samples were represented by fibroadenoma, enign dysplasia and ductal-lobular hyperplasia.

Raman spectra of the breast tissue were measured with Ramanor U1000 (Jobin Yvon) and Spectra Physics 2017-04S argon ion laser operating at $514 \mathrm{~nm}$ and $488 \mathrm{~nm}$ at the output power of $25 \mathrm{~mW}$ and $100 \mathrm{~mW}$, respectively. The laser spot is $d=500 \mu \mathrm{m}$ in diameter. Light diffusion in the biological tissue results in a sampled diameter of $d \approx 1 \mathrm{~mm}$. The integration time is $0.5 \mathrm{~s}$ at the spectral resolution of $8 \mathrm{~cm}^{-1}$. The reproducibility of data for the breast tissue has been examined carefully to avoid photoisomerization or photodecomposition caused by irradiation with the laser beam. The power density of the laser beam was kept as low as possible in Raman measurements to avoid or minimize degradation of the sample. We have never seen photochemical instability at energies below $100 \mathrm{~mW}$, but for security reasons the output power of the laser was reduced to $25 \mathrm{~mW}$ (directly at the sample $14 \mathrm{~mW}$ ). The spectra have been recorded in the range of $200-8000 \mathrm{~cm}^{-1}$ and of $200-3600 \mathrm{~cm}^{-1}$ at the laser output of $25 \mathrm{~mW}$ and $100 \mathrm{~mW}$.

\section{Results}

Figure 1 compares the Raman spectra for the normal and the benign lesion. One can clearly see the significant differences in the spectra of the normal tissue and the benign tissue. Firstly, only the normal tissue exhibits the Raman peaks in contrast to the benign tissue which is characterized only by autofluorescence of the tissue. Secondly, no Raman peaks can be seen in the benign tissue although both tissues have comparable intensities of autofluorescence.

The characteristic set of the Raman peaks that can be seen in the normal tissue (and are not visible in the abnormal tissue of the same patient) is represented mainly by the $\mathrm{C}-\mathrm{C}\left(1150 \mathrm{~cm}^{-1}\right)$ and $\mathrm{C}=\mathrm{C}$ $\left(1520 \mathrm{~cm}^{-1}\right)$ stretching vibration of carotenoids and the $\mathrm{C}-\mathrm{H}$ symmetric and asymmetric vibrations of lipids (fat) at $2850-2940 \mathrm{~cm}^{-1}$. As it is well known many structures in the breast tissue, for example, phospholipid bilayers, are responsible for most of the compartmentalization within cells, whereas the lipophilic carotenoids are bound to the sub-cellular structures. Scheme 1 presents $\beta$-carotene (a) and phosphatidylcholine (b).

In Fig. 2 we compare the Raman spectra for the normal and the malignant tissue (infiltrating ductal cancer). Again, one can easily see the significant differences in the Raman spectra of the normal tissue 


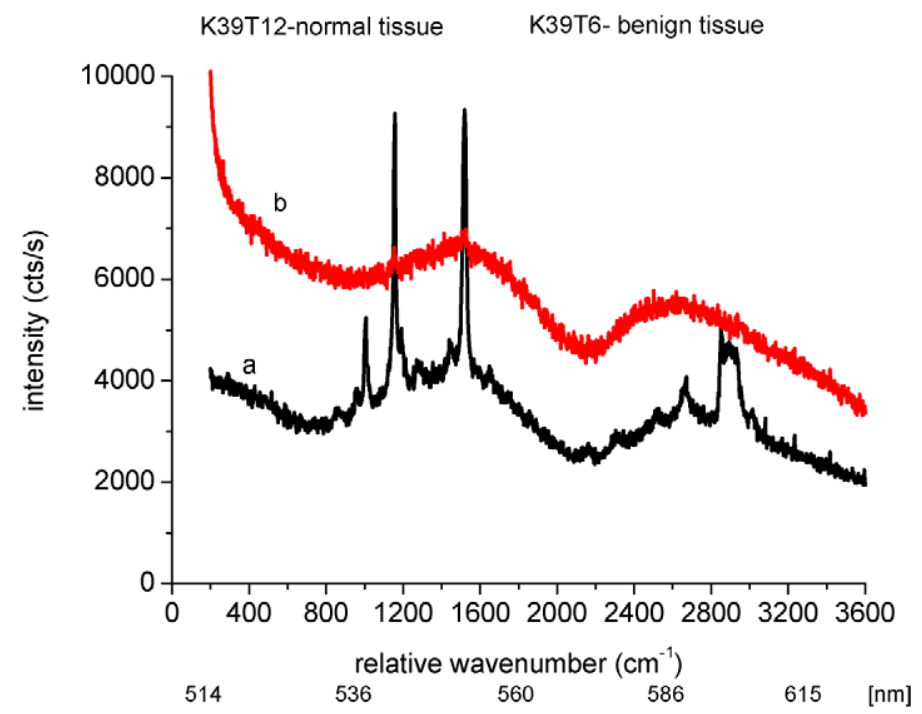

Fig. 1. Raman spectra of the normal (a) and the benign (b) tissues (dysplasia of the breast) of the same patient at $100 \mathrm{~mW}$.

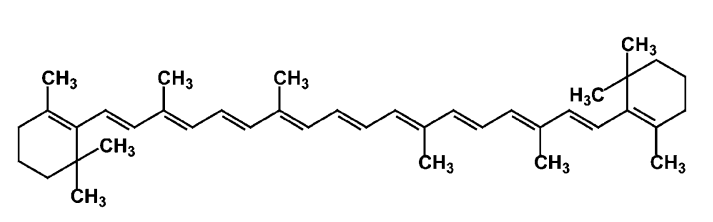

(a)

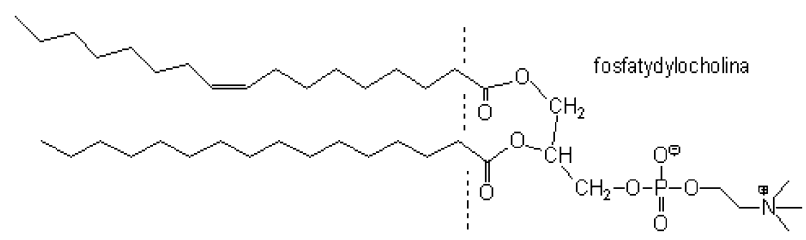

(b)

Scheme 1. Structure of (a) $\beta$-carotene, (b) phosphatidylcholine.

and the malignant tissue. The normal tissue has the characteristic Raman bands of carotenoids and lipids which are not visible in the malignant tumor tissue.

In most samples the normal breast tissue has autofluorescence lower than the malignant tissue of the same patient, but for certain samples the autofluorescence of the malignant tissue is comparable or even lower as in Fig. 3. However, even in these cases the characteristic Raman bands can be seen only in the normal breast tissue of the patient.

It appears that changes in autofluorescence are at least as characteristic of the state of the tissue as the Raman bands of carotenoids and lipids. The results presented in Figs 1-3 provoke a question:

Does the lack of the characteristic Raman peaks in the abnormal tissue indicate that the concentrations of carotenoids and lipids (fat) are lower in the abnormal tissue or the Raman peaks are simply hidden in the background autofluorescence of the tissue?

From the diagnostic point of view this question is not quite essential. To find a marker it is enough to say - the peaks are visible in the normal tissue whereas they are not observed in the malignant one and make effort to find a qualitative way of estimation. However, answering this question is important for cancer science, because it may help to understand molecular mechanisms which drive the transformation of normal human cells into malignant derivatives.

Figures 2 and 3 may help to find the answer to the above mentioned question. Figure 2 represents the case where both types of tissues have nearly identical and relatively high autofluorescence. One can see 


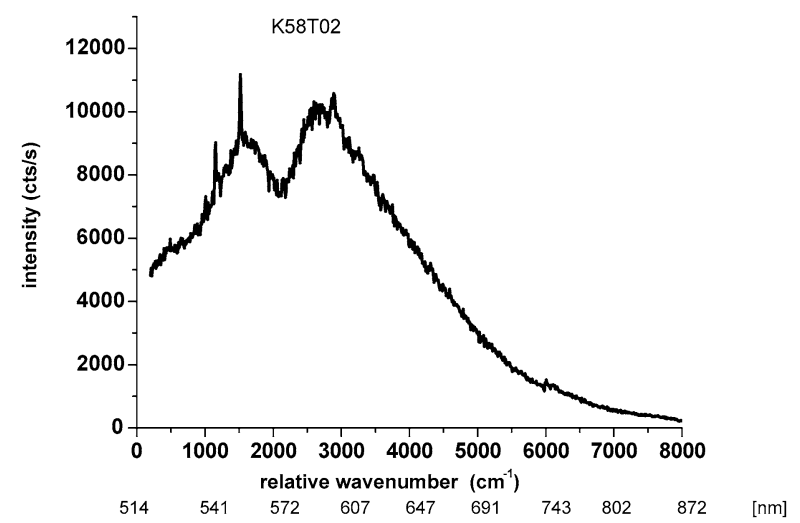

(a)

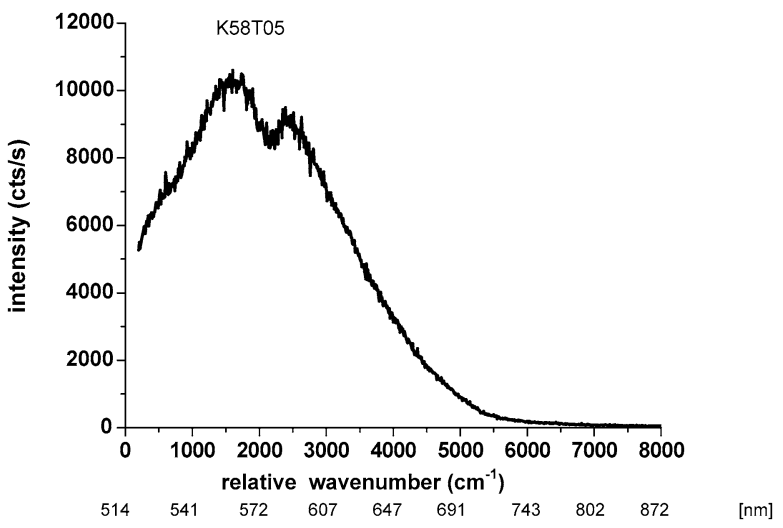

(b)

Fig. 2. Raman spectra of the normal (a) and the malignant (b) (infiltrating ductal cancer) tissues of the same patient at $100 \mathrm{~mW}$.

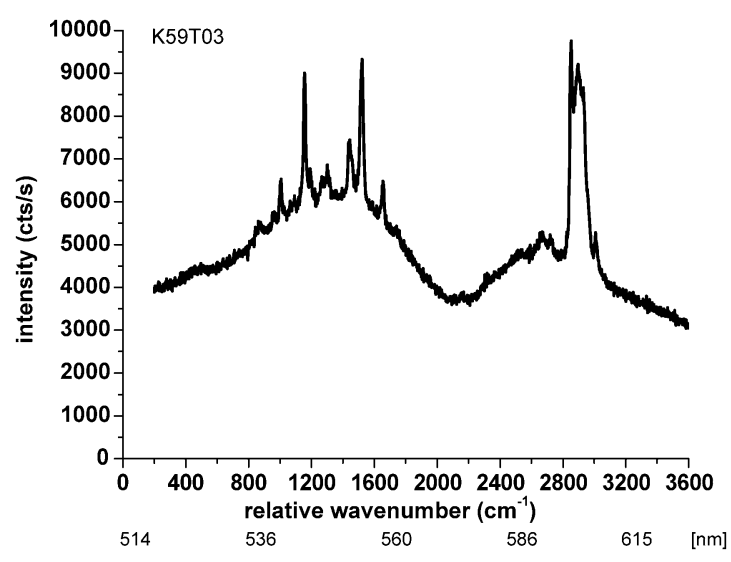

(a)

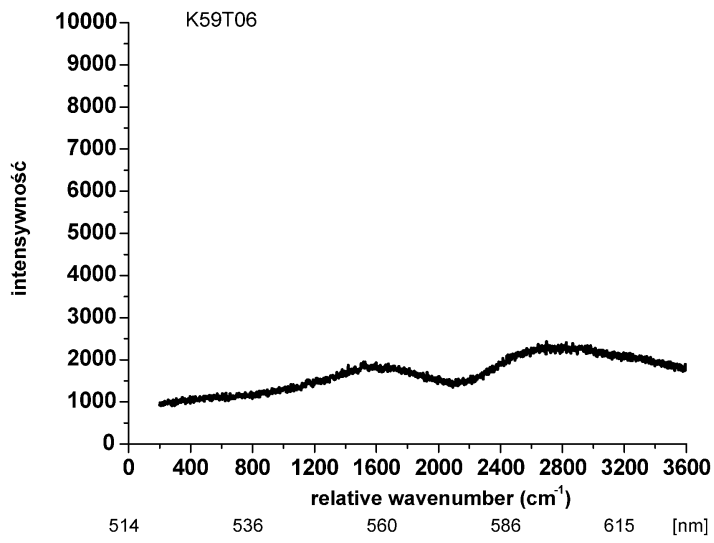

(b)

Fig. 3. Raman spectra of the normal (a) and the malignant (b) (infiltrating ductal cancer) tissues of the same patient at $100 \mathrm{~mW}$.

that in spite of the comparable autofluorescence of the malignant tissue with respect to the normal tissue at around $560 \mathrm{~nm}$, only the normal tissue shows the Raman peaks of carotenoids. Figure 3 demonstrates the sample where the autofluorescence of the malignant tissue is even lower than that of the normal tissue of the same patient, but the characteristic Raman bands of carotenoids and lipids can be seen only in the normal breast tissue.

The results presented in Figs 2 and 3 provide evidence that the lack of the characteristic peaks in the malignant tissue simply demonstrates the disappearance or decrease of the bands of carotenoids and lipids in the malignant tissue. Additionally, in most cases they are partially hidden in the high background of the malignant tissue autofluorescence.

It is important to understand the origin of the tissue autofluorescence. The autofluorescence peak with maximum at $560 \mathrm{~nm}$ may be partially related the tissue blood with heamoglobin as a predominant fluorophore $\left(\beta Q_{1}\right.$ band, $\left.540 \mathrm{~nm}\right)$ and $\left(\alpha Q_{1}\right.$ band, $\left.560 \mathrm{~nm}\right)$. To estimate the contribution of blood to the tissue autofluorescence we have measured the Raman spectra of the blood (as well as the separated components such as the blood cells and the blood plasma) from the circulatory blood vessels for each patient. Figure 4(a) presents the comparison between the Raman spectra of the fresh ex vivo normal tissue, the 


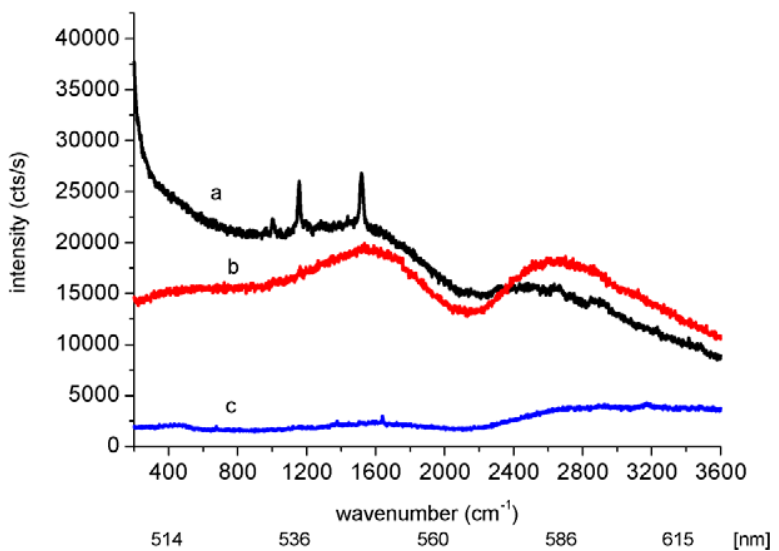

(a)

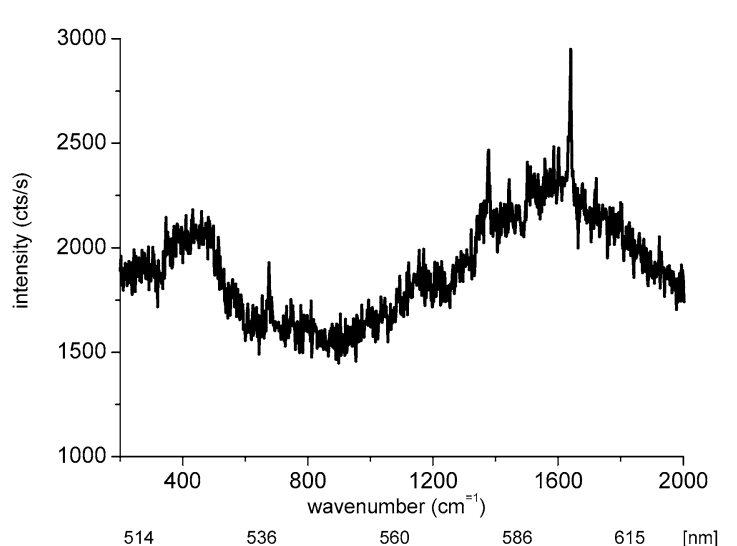

(b)

Fig. 4. Comparison between the Raman spectra of the fresh ex vivo (a) normal and (b) malignant tissue, (c) blood, of the same patient at $25 \mathrm{~mW}$ (a), Raman spectra of blood of the same patient at $100 \mathrm{~mW}$ (b).

malignant tissue and the blood cells from the circulatory blood vessels of the same patient. One can see that the fluorescence from the blood is much lower than the autofluorescence of the malignant tissue and of the normal tissue as presented in Fig. 4(a) and do not obviously dominate the autofluorescence of the tissue. Moreover, the blood has its own pattern of the characteristic peaks dominated by the bands of proteins (1440-1460 $\mathrm{cm}^{-1}$ and $\left.1650-1680 \mathrm{~cm}^{-1}\right)$ and hemoglobine $\left(1370 \mathrm{~cm}^{-1}\right)$ (Fig. 4(b)) in contrast to the normal breast tissue that is dominated by the bands of carotenoids $\left(\mathrm{C}-\mathrm{C}\left(1150 \mathrm{~cm}^{-1}\right)\right.$ and $\mathrm{C}=\mathrm{C}\left(1520 \mathrm{~cm}^{-1}\right)$ stretching vibration and of lipids (at $2850-2940 \mathrm{~cm}^{-1}$ for the $\mathrm{C}-\mathrm{H}$ symmetric and asymmetric vibrations).

To learn more about the origin of the tissue autofluorescence (other than from the blood) we have concentrated on the fluorescence of the main components of the tissue. As it is well known the main components of the tissue: collagene, epithelial cell cytoplasm, cell nucleus, calcium oxalate dehydrate, calcium hydroxyapatite, $\beta$-carotene, cholesterol do not have emission in the visible region, except of flavins and carotenoids. The other components of the biological tissue such as tryptophan, pyridoxine elasitin, collagen, NADH exhibit emission at shorter wavelengths. However, majority of the biological tissue components can be precursors of fluorescent products. As our results presented so far provide a strong indication that the bands of carotenoids show a specificity for the normal and abnormal tissue we have concentrated on the fluorescence from carotenoids. We have measured the resonance Raman spectra of carotenoids in biological matrices of carrot to compare them with the bands of carotenoids observed in the breast tissue [34] as a function of the irradiation dose of the gamma-irradiation. We have shown that the maximum of the fluorescence peak at $560 \mathrm{~nm}$ for the carotenoids in the biological matrix of carrot is exactly at the same wavelength as for the malignant breast tissue. Moreover, the picture that emerges from the detail analysis of the results presented in [34] provides indication that the disappearance of carotenoids and the fluorescence increase in the malignant tissue may be related to free radical oxidation of pigments such as carotenoids. Moreover, lipids can be precursors of fluorescent products. The disappearance of the lipid bands in the tumor tissue (the band at $2850-2940 \mathrm{~cm}^{-1}$ ) is related to lipid peroxidation by reactive oxygen (superoxide anion radical $\mathrm{O}_{2}^{-}$) or their iron complexes that leads to lipid hydroperoxides and cyclic peroxides, which are further decomposed, or degradated into various saturated and unsaturated carbonyl compounds, mainly, aldehydes. Unsaturated aldehydes are often cytoxic or genotoxic [31]. 
In the view of this suggestion we can go one step further and attract attention to the other phenomenon which is apparently beyond the scope of this study- the age-related progressive accumulation of pigments. The age-related progressive accumulation of pigments is a consistently recognized phenomenon in men and animals and is regarded as a hallmark of aging [31]. The pigments may occupy up to $40 \%$ of the cytoplasmic volume in post-mitotic cells of old animals. Although intensive studies including morphological, pathological and biochemical research of these enigmatic substances have been carried out for more than a century, the biochemistry and formation are still a matter of debate and controversy. The age-related pigments (APF-age-pigment like fluorophores) are classically known as "lipofucsin". They can be produced from a variety of biological materials including carotenoids, lipids, proteins, carbohydrates, ascorbic acid, possibly nucleic acids. A majority of them are precursors of fluorescent products. However, it has been shown that only lipids and carotenoids are precursors for the fluorescent products that have emission around $560 \mathrm{~nm}$ [31] that cover the region of the malignant breast tissue autofluorescence. To summarize this part of the discussion, our results combined with the above mentioned results from literature strongly suggest that the characteristic Raman bands of carotenoids and lipids observed in the normal breast tissue samples disappear followed by increasing autofluorescence of their radical products in the malignant breast tissue. The Raman and autofluorescence breast tissue results presented in the paper provide some contribution to the hypothesis that the tumorigenesis in humans is a multistep process like aging with accumulation of age-related pigments fluorophores. The free radical theory of aging, proposed by Harman in 1956 is now one of the leading theories explaining the biochemical basis of age-related pigments formation. Our Raman results presented here provide some hints that the same theory may explain many of the processes that drive the progressive transformation of normal human cells into highly malignant derivatives.

\section{Interpretation of the Raman spectra for the breast tissue samples by PCA statistical methods}

The Raman spectra have been analyzed using the principal component analysis (PCA) and MATHLAB least-squares fitting algorithm [35]. This is a statistical method that helps in visualization experimental data. Indeed, when we have a large amount of samples and each of them contains a lot of information in each spectrum we need any method that will help to extract the most important features or components. The most frequently used method in this respect is principal component analysis, with each Raman spectrum represented as a vector of intensity values corresponding to each wavelength. The PCA score plot (model - SNV, mean center, first derivative) for all the recorded Raman spectra and all the samples has been obtained [35]. We have found that the samples have been separated along the PC1 and PC2 components into the three characteristic groups - normal, malignant and benign tissues. The physical meaning of the PC1 and PC2 components has been established from the loading plots. We have found that the $\mathrm{PC} 1$ component is related to the characteristic Raman peaks: $\mathrm{C}-\mathrm{C}$ and $\mathrm{C}=\mathrm{C}$ stretching bands of carotenoids and $\mathrm{C}-\mathrm{H}$ symmetric and asymmetric bands of lipids (fats). The PC2 component is related to the autofluorescence of the tissues.

Figure 5 shows the plot of the intensity of the Raman peak of the $\mathrm{C}=\mathrm{C}$ stretching mode of carotenoides at $1520 \mathrm{~cm}^{-1}$ vs. the autofluorescence of the sample at $1520 \mathrm{~cm}^{-1}$. One can see that the malignant tissue samples are situated almost exclusively along the $y$ axis for which the Raman intensity is zero (the Raman peaks are not observed). In contrast to the malignant tissue the normal tissue samples are spread in the area between the $y$ and $x$ axes. The benign tissue samples are mostly situated close to $(0,0)$ area (low autofluorescence, no Raman peaks). 


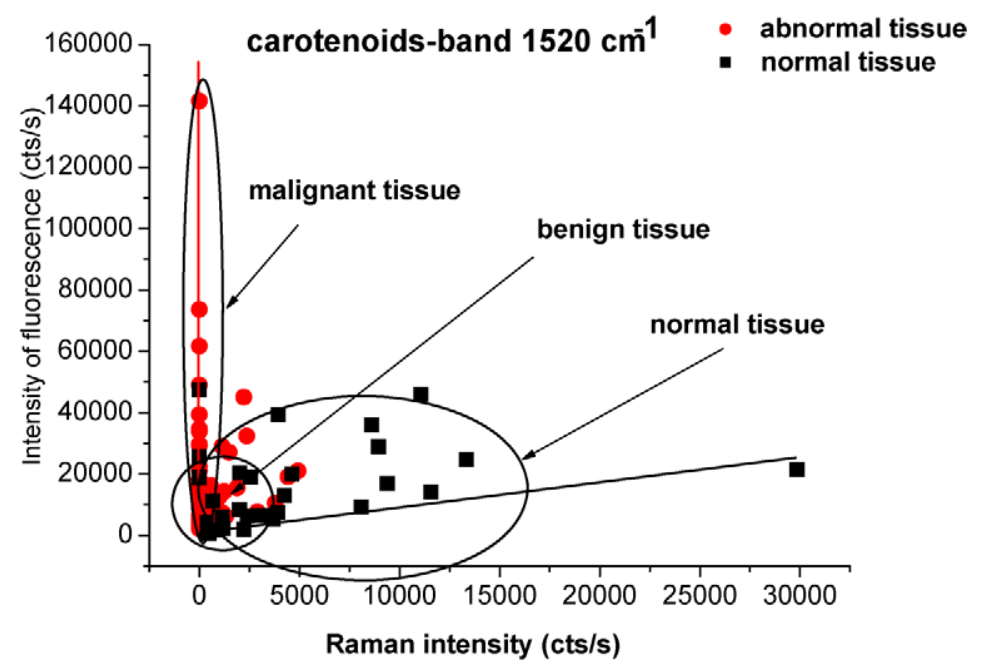

Fig. 5. 2D plot of the autofluorescence intensity vs. the Raman band intensity at $1520 \mathrm{~cm}^{-1}$.

Comparing the Raman spectra with the histopatological description provided by the hospital we have evaluated the sensitivity and the specificity of the studied samples taking into account the first principal component PC1 - the characteristic Raman peaks.

The sensitivity has been calculated as the proportion of the samples with a positive test result (lack of the Raman peaks) to the total number of the samples that have the target disorder (malignant tissue or benign tissue). We have found the sensitivity of $81 \%$ for the malignant tissue and of $66 \%$ for the benign tissue.

The specificity have been calculated as the proportion of the samples with a negative test result (appearance of the Raman characteristic peaks) to the total number of the samples that do not have the target disorder (normal tissue). We have found the specificity for the normal tissue of $88 \%$.

The similar calculations of sensitivity have been performed with respect the second principal component PC2 - autofluorescence of the sample. The sensitivity has been calculated as the proportion of the samples with a positive test result (autofluorescence of the malignant (or benign) tissue higher by $100 \%$ than that of the normal tissue of the same patient) to the total number of the pair samples (abnormal and normal for the same patient) that have the target disorder (malignant (or benign) tissue). We have found the sensitivity of 55\% for the malignant tissue and of 32\% for the benign tissue. The sensitivity has been calculated as the proportion of the samples with a negative test result (lack of the Raman peaks) to the total number of the samples that do not have the target disorder (normal tissue).

\section{Conclusions}

The Raman results for the normal, malignant and benign breast tissue presented here can be summarized as the following:

1. The results presented in the paper provide the Raman markers - the characteristic Raman peaks and the autofluorescence of the sample - that can be useful for the preclinical and clinical in vivo breast tissue studies with Raman spectrometer coupled to the probe via the optical fiber designed for medical applications. 
2. At the laser excitation of $514 \mathrm{~nm}$ the normal breast tissue has a characteristic set of Raman bands: $\mathrm{C}-\mathrm{C}$ and $\mathrm{C}=\mathrm{C}$ stretching bands of carotenoids and $\mathrm{C}-\mathrm{H}$ symmetric and asymmetric bands of lipids (fats) which are not visible in the malignant tissue and in the benign tumor tissue.

3. The normal tissue has lower autofluorescence than the malignant tissue, the benign tumor tissue has autofluorescence similar to that of the normal tissue.

4. The results clearly illustrate very good discrimination of normal and pathological tissue and the ability of Raman spectroscopy to accurately diagnose breast cancer. Moreover, the results demonstrate how the diagnostic scheme can be adjusted to obtain the desired degree of sensitivity and specificity. We have found the sensitivity of $81 \%$ for the malignant tissue and of $66 \%$ for the benign tissue and the specificity for the normal tissue of $88 \%$ with respect to the first PCA component the characteristic Raman peaks. We have found the sensitivity of $81 \%$ for the malignant tissue and of $66 \%$ for the benign tissue and the specificity for the normal tissue of $88 \%$ with respect to the second PCA component - the autofluorescence of the sample. Combining the sensitivity and specificity with respect the PCA1 and PCA2 components may help to discriminate between the malignant and benign tissue.

5. The results presented here support earlier investigations from the other laboratories $[6,18]$ that the Raman spectra for the normal tissue are dominated by lipids, whereas they reveal significant discrepancy related to the role of carotenoids as a possible Raman markers. According to the micro-spectroscopic model of human breast tissue proposed recently by Shafer-Pelitier et al. [8] carotenoids show no or minor specificity and cannot be treated as a marker for discrimination of normal, benign and malignant breast tissue. In contrast to the results presented by Shafer-Pelitier et al. [8] our results demonstrate that Raman bands of carotenoids combined with the autofluorescence of the tissue exhibit key features to diagnose malignancy. Moreover, the Raman spectra with excitation in the visible range have a potential to monitor processes related to forming new blood vessels due to angiogenesis.

6. The results presented in the paper correspond very well to the recent screening studies focusing on how and when cancers were found over eight years in existing records of 1,112 women collected between 1981 and 2006 [36]. According to their report cancer turns up five times more often in women with extremely dense breasts than in those with the fatty breast tissue. Breast density comes from the presence of more connective, duct-lining and milk-gland tissue other than fat.

7. The Raman and autofluorescence breast tissue results presented in the paper provide some contribution to the hypothesis that the tumorigenesis in humans is a multistep process like aging with accumulation of age-related pigments fluorophores. The free radical theory of aging, proposed by Harman in 1956 is now one of the leading theories explaining the biochemical basis of age-related pigments formation. Our Raman results presented here provide some hints that the same theory may explain many of the processes that drive the progressive transformation of normal human cells into highly malignant derivatives.

\section{Acknowledgement}

We gratefully acknowledge the support of this work through the grant Nr3 T11E 04729 in 2005-2008 and the Dz. St. 2007. The support from Marie Curie Chair MEXC-CT-2006-042630 is also acknowledged. 


\section{References}

[1] R.R. Alfano, C.H. Liu, W.L. Sha, H.R. Zhu, D.L. Akins, J. Cleary, R. Prudente and E. Cellmer, Laser Life Sci. 4 (1991), 23-28.

[2] D.C.B. Redd, Z.C. Feng, K.T. Yue and T.S. Gansler, Appl. Spectrosc. 47 (1993), 787-791.

[3] C.J. Frank, D.C.B. Redd, T.S. Gansler and R.L. McCreery, Anal. Chem. 66 (1994), 319-326.

[4] C.J. Frank, R.L. McCreery and D.C.B. Redd, Anal. Chem. 67 (1995), 777-783.

[5] R. Monoharan, K. Shafer, R.T. Perelman, J. Wu, K. Chen, G. Deinum, M. Fitzmaurice, J. Myles, J. Crowe, R.R. Dasari and M.S. Field, Photochem. Photobiol. 67 (1998), 15-22.

[6] J.T. Motz, S.J. Gandhi, O.R. Scepanovic, A.S. Haka and J.R. Kramer, J. Biomed. Opt. 10 (2005), 031113.

[7] L.-P. Choo-Smith, H.G.M. Edwards, H.P. Endtz, J.M. Kros, F. Heule, H. Barr, J.S. Robinson Jr., H.A. Bruining and G.J. Puppels, Biopolymers 67 (2002), 1-9.

[8] K.E. Shafer-Peltier, A.S. Haka, M. Fitzmaurice, J. Crowe, J. Myles, R.R. Dasari and M.S. Feld, J. Raman Spectrosc. 33 (2002), 552-563.

[9] R. Baker, P. Matousek, K.L. Ronayne, A.W. Parker, K. Rogers and N. Stone, The Analyst 132 (2007), 48-53.

[10] R.A. Bitar Carter, A.A. Martin, M.M. Netto and F.A. Soares, A. Mahadevan-Jansen, M.G. Sowa, G.J. Puppels, Z. Gryczinski, T. Vo-Dinh and J.R. Lakowicz (eds), Proceedings of the SPIE 5321 (2004), 190-197.

[11] C.A. Owen, I. Notingher, R. Hill, M. Stevens and L. Hench, Mater. Med. 17(5) (2006), 1019-1023.

[12] A.S. Haka, Z. Volynskaya, J.A. Gardecki, J. Nazemi, D. Hicks, M. Fitzumaurice, R.R. Dasari, J.P. Crowe and M.S. Feld, Cancer Res. 66 (2006), 3317-3322.

[13] A.S.H. Haka, K.E. Shafer-Peltier, M. Fitzmaurice, J. Crowe, R.R. Dasari and M.S. Feld, Proc. Natl. Acad. Sci. USA 102 (2005), 12371-12376.

[14] A.S.H. Haka, K.E. Shafer-Peltier, M. Fitzmaurice, J. Crowe, R.R. Dasari and M.S. Feld, Cancer Res. 62 (2002), 53755380.

[15] K.E. Shafer-Peltier, A.S. Haka, J.T. Motz, M. Fitzmaurice, R.R. Dasari and M.S. Feld, J. Cell. Biochem. 87 (2002), S125S137.

[16] J. Kneipp, B.S. Tom, M. Kliffen, M.P. Marian and G. Puppels, Vib. Spectrosc. 32 (2003), 67-74.

[17] R. Manoharan, K. Shafer, I. Perelman, J. Wu, K. Chen, G. Deinum, M. Fitzmaurice, J. Myles, J. Crowe, R.R. Dasari and M.S. Feld, Photochem. Photobiol. 67 (1998), 15-22.

[18] E.B. Hanlon, R. Manoharan, T.W. Koo, K.E. Shafer, J.T. Motz, M. Fitzmaurice, J.R. Kramer, I. Itzkan, R.R. Dasari and M.S. Feld, Phys. Med. Biol. 45 (2000), R1-R59.

[19] N.K. Afseth, V.H. Segtnan and J.P. Wold, Appl. Spectrosc. 60 (2006), 1358-1367.

[20] M.V.P. Chowdary, K. Kalyan Kumar, J. Kurien, S. Mathew and C.M. Krishna, Biopolymers 83 (2006), 556-569.

[21] H. Abramczyk, I. Placek, B. Brożek-Płuska, K. Kurczewski, Z. Morawiec and M. Tazbir, in: Proceedings of the Conference on the Spectroscopy of Biological Molecules, Paris, 1-6 September, 2007.

[22] H. Abramczyk, I. Placek, B. Brożek-Płuska, K. Kurczewski, Z. Morawiec and M. Tazbir, in: Proceedings of the 13th International Congress of Radiation Research, San Francisco, 8-12 July, 2007.

[23] H. Abramczyk, I. Placek, B. Brożek-Płuska, K. Kurczewski, Z. Morawiec and M. Tazbir, in: Proceedings of the International Conference of Computational Methods in Sciences and Engineering, Corfu, Greece, 25-30 September, 2007.

[24] H. Abramczyk, I. Placek, B. Brożek-Płuska, K. Kurczewski, Z. Morawiec and M. Tazbir, in: Proceedings of the Conference Recent Advances in Laser Spectroscopy and Laser Technology, Lodz, Poland, 29-31 May, 2007.

[25] H. Abramczyk and K. Paradowska-Moszkowska, J. Chem. Phys. 24 (2001), 11221-11227.

[26] H. Abramczyk and K. Paradowska-Moszkowska, J. Chem. Phys. 265 (2001), 177-191.

[27] H. Abramczyk, K. Paradowska-Moszkowska and G. Wiosna, J. Chem. Phys. 118 (2003), 4169-4175.

[28] D. Hanahan and R.A. Weinberg, Cell 100 (2000), 57-70.

[29] M. Arkin, Curr. Opin. Chem. Biol. 9 (2005), 317-324.

[30] G.P. Gupta and J. Massague, Cell 127 (2006), 679-695.

[31] D. Yin, Free Rad. Biol. Med. 21 (2006), 871-888.

[32] H. Abramczyk, M. Kolodziejski and G. Waliszewska, J. Mol. Liquids 79 (1999), 223-233.

[33] L. Calucci, C. Pinzino, M. Zandomeneghi, A. Capocchi, S. Ghiringhelli, F. Saviozzi, S. Tozzi and L. Galleschi, J. Agric. Food Chem. 51(4) (2003), 927-934.

[34] B.G.M. Vandeginste, D.L. Massart, L.M.C. Buydens, S. de Jong, P.J. Lewi and J. Smeyers-Verbeke, Handbook of Chemometrics and Qualimetrics, Part B, Elsevier, Amsterdam, 1998.

[35] H. Abramczyk, I. Placek, B. Brożek-Płuska, K. Kurczewski, Z. Morawiec and M. Tazbir, J. Phys. Chem. (2007), submitted.

[36] N.F. Boyd, H. Guo, L.J. Martin, L. Sun, J. Stone, E. Fishell, R.A. Jong, H. Hislop, A. Chiarelli, S. Minkin and M.J. Yaffe, N. Engl. J. Med. 3 (2007), 227-236. 


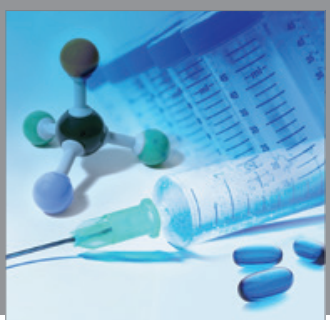

International Journal of

Medicinal Chemistry

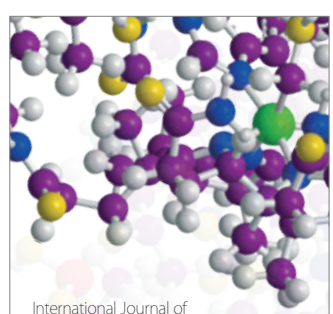

Carbohydrate Chemistry

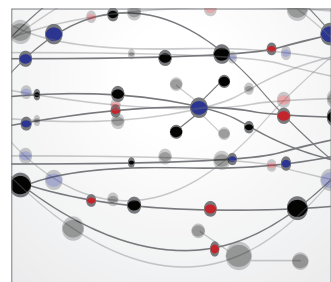

The Scientific World Journal
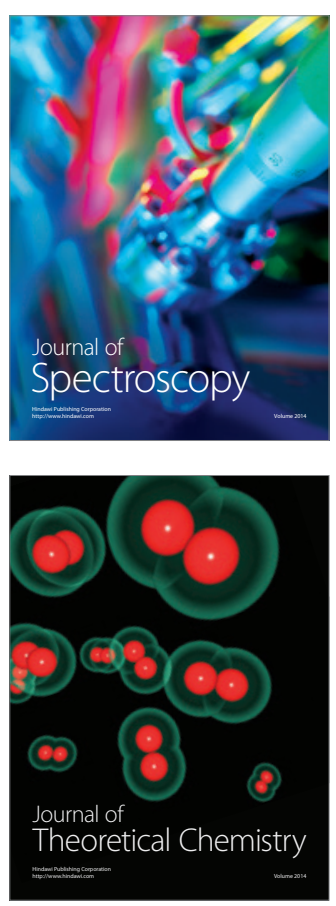
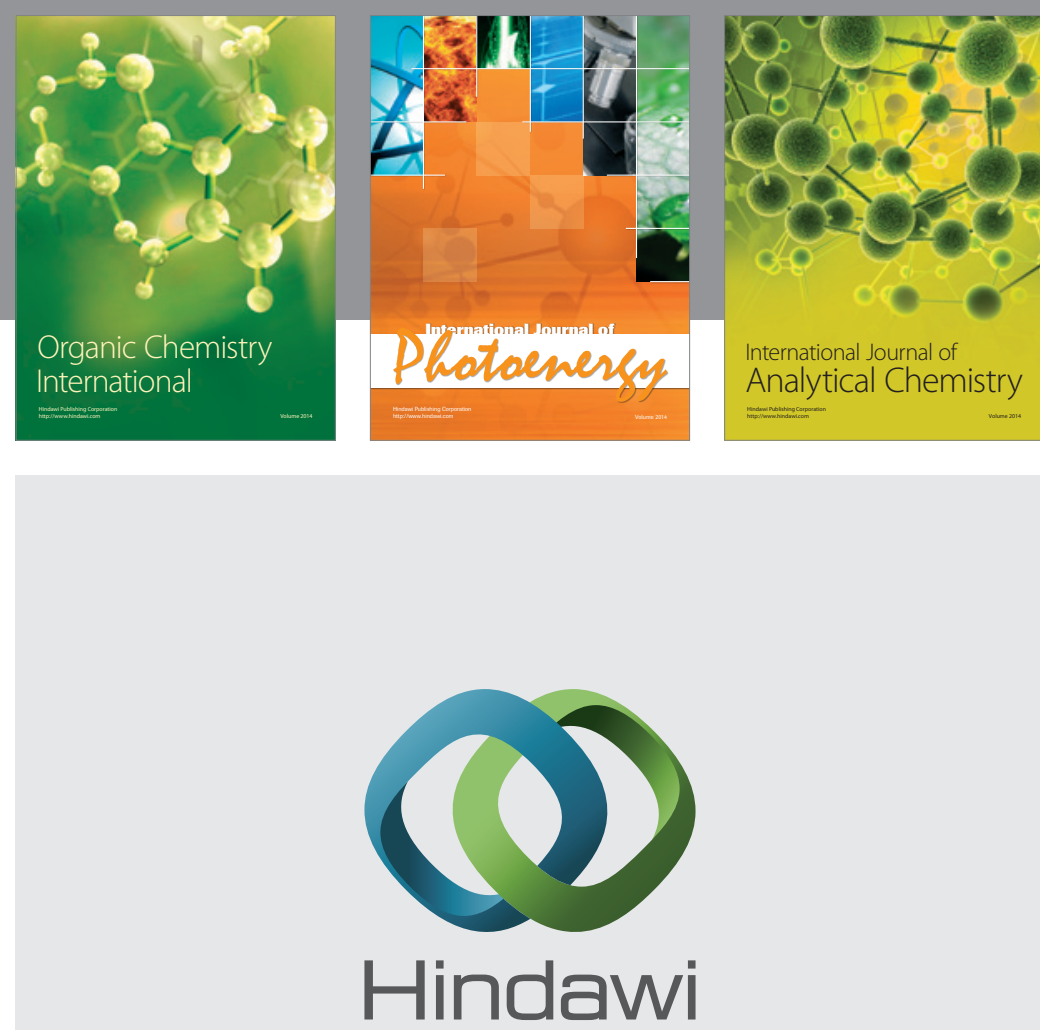

Submit your manuscripts at

http://www.hindawi.com
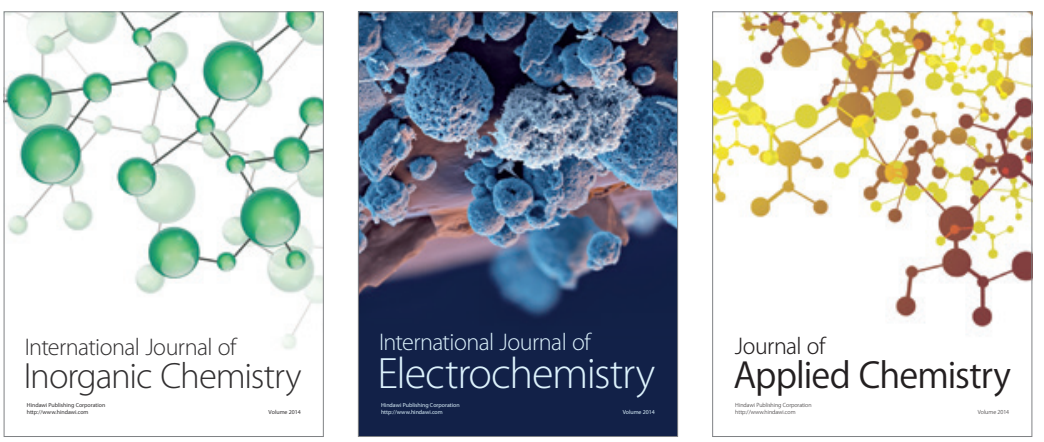

Journal of

Applied Chemistry
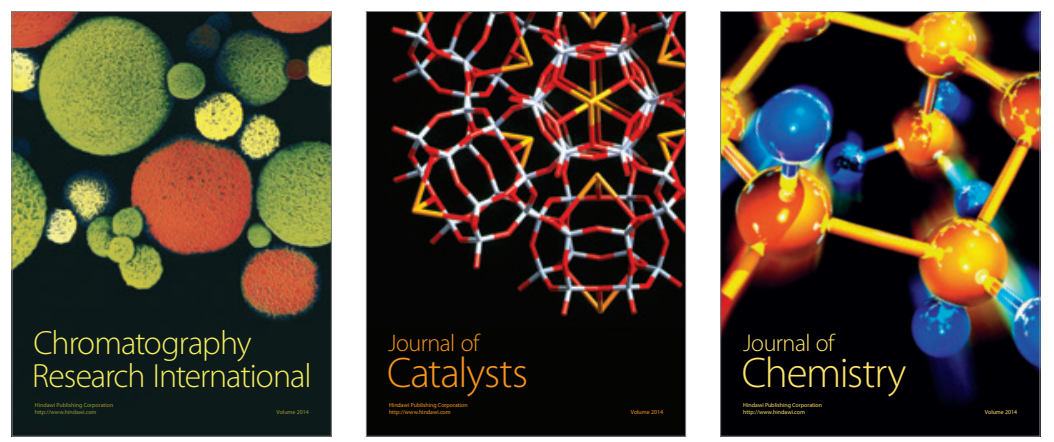
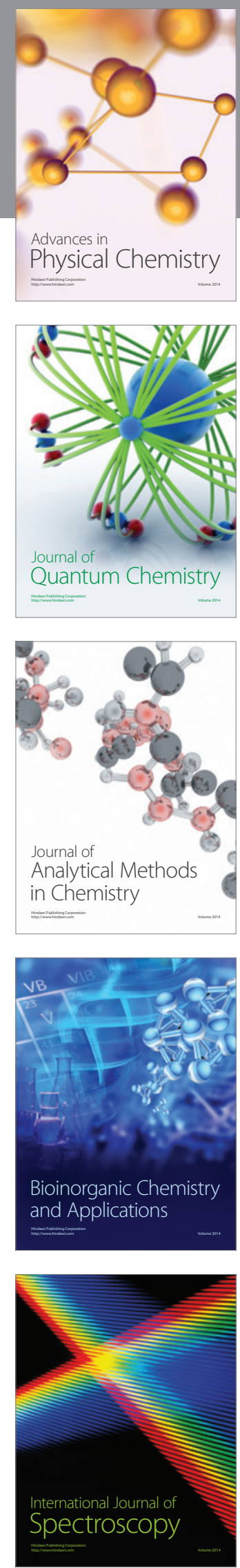